\title{
On the usefulness of the Theory of Planned Behaviour for fertility research
}

\author{
Aart C. Liefbroer *
}

Like so many words that are bandied about, the word theory threatens to become meaningless. Because its referents are so diverse - including everything from minor working hypotheses, through comprehensive but vague and unordered speculations, to axiomatic systems of thought - use of the word often obscures rather than creates understanding. (Merton 1968, p.39)

\section{Introduction}

In their contribution to last year's VID conference on From intentions to behaviour: reproductive decision-making in a macro-micro perspective, reproduced in this volume, Morgan and Bachrach (2011) raise the question whether the Theory of Planned Behaviour (TPB), developed by Icek Ajzen and Martin Fishbein (Fishbein and Ajzen 1975, 2010; Ajzen 1985) is an appropriate model for human fertility. Their assessment is that it is of some use, especially "when dealing with questions that address short-term influences on fertility behaviour which are not closely tied to macro-level structural constraints" (Morgan and Bachrach 2011). However, they advocate the use of more general, "next-generation", models of fertility and in particular the Theory of Conjunctural Action that they developed (Johnson-Hanks et al. 2011) as a more promising alternative.

I tend to disagree with the conclusion drawn by Morgan and Bachrach MandB from here on - and with most of the arguments they provide to arrive at that conclusion. That I disagree with them may not come as a surprise, given that Jenny de Jong Gierveld and I (De Jong-Gierveld and Liefbroer 1988) already advocated the use of the TPB for understanding demographic decision-making 23 years ago, and that I have been applying ideas from the TPB to topics like leaving home (Billari and Liefbroer 2007), union formation (Liefbroer and De Jong Gierveld 1993; Liefbroer et al. 1994) and fertility (Liefbroer 2005). Moreover, I act as scientific coordinator of the Generations and Gender Programme, in which a survey is used that extensively draws on the TPB in its conceptualisation and in the operationalisation of its measurement instruments (Dommermuth et al. 2011; Klobas 2010; Vikat et al. 2007). From this background, I will reflect on the

\footnotetext{
* Aart C. Liefbroer, Head of the Department of Social Demography, Netherlands Interdisciplinary Demographic Institute, The Hague, The Netherlands, and Professor at the Department of Sociology, VU University Amsterdam, The Netherlands. Email: liefbroer@nidi.nl
} 
usefulness of the TPB and will arrive at conclusions that are quite strongly at odds with those of MandB. I will first reflect on the more general question what sort of theory the TPB is and next discuss more specific issues like the centrality of the notion of intention, the alleged static nature of the theory and the role of macro context in the TPB.

\section{Theory, what theory?}

A first issue that needs to be resolved in evaluating the usefulness of the TPB is what kind of theory it is. Merton - quoted above - defines theory as "logically interconnected sets of propositions from which empirical uniformities can be derived" (Merton 1968, p. 39). But at the same time, both Merton and many other scholars (e.g. De Bruijn 1999) are aware of the fact that theories can operate at very different levels of abstraction. Stinchcombe (1968) distinguishes seven levels of generality, Swanborn (1990) lists six main conceptions of substantive theories, and Merton (1968) himself expresses a preference for theories of the middle range, located between simple working hypotheses developed in ongoing research and systematic theories that are able to explain uniformities across a large range of social phenomena.

Although these examples make it clear that a wide variety of theoretical levels could be distinguished, I will limit myself to a relatively simple distinction between two levels of generality. The first level is that of theories proper which consists of (i) definitions of concepts and (ii) statements about the interrelatedness between these concepts. In principle - with the help of (iii) operational definitions of the key concepts - such a theory should give rise to the formulation of testable hypotheses. The second level is that of what could be called theoretical or heuristic frameworks, that do not lend themselves so well to direct testing, but sensitise scientists to those elements in a situation that are important to consider in order to explain a specific phenomenon.

Most scientists would consider the TPB as a theory proper, and for good reasons. It has clear definitions of its key concepts and clear statements about their interrelatedness. At the same time, Fishbein and Ajzen have developed a set of operational definitions of the key concepts that allow for quite specific operationalisation and related hypotheses testing. Hypotheses derived from the theory have been tested in a wide variety of settings and research has shown that the theory - at least if used in conjunction with the operational definitions and within the right scope - has a strong potential of correctly predicting regularities in the data.

Yet, I would rather prefer to view the TPB as a heuristic framework than as a theory. This preference is based on both negative considerations (the attractiveness of the TPB as a theory is relatively low) and positive considerations (the attractiveness of the TPB as a heuristic framework is relatively high). The attractiveness of the TPB as a theory is reduced by the fact that it is hard to falsify. For instance, if one finds that intentions are not completely determined by 
attitudes, norms and perceived behavioural control, the natural reaction is not to doubt that the theory is correct, but rather to assert that the central concepts have been measured suboptimally. This could result from 'incorrect' formulation of the elements of the theory ("wrong question wording") or from 'incorrect' selection of arguments that together constitute a concept in the theory ("wrong arguments"). This leads to a kind of immunisation of the theory. It becomes hard or even impossible to falsify it. Another drawback of the TPB as a theory is that it does not really specify which arguments need to be fed into the model. For instance, the attitude towards childbearing is conceptualised as resulting from the expected consequences of having a child. However, the theory does not specify what consequences are important to take into consideration. In that sense, it is an 'empty' theory. This is no problem, as long as users realise that (i) the arguments that are used in the model have to be derived from theoretical reasoning, and (ii) establishing the relevance of specific arguments in understanding fertility behaviour is much more important than 'just' establishing that attitudes or norms play a role. One wants to know whose norms are important and what perceived consequences of having a child influence that decision (e.g. Liefbroer 2005). At the same time, I feel that the TPB has a high level of attractiveness as a heuristic framework. First, it suggests that fertility is influenced by three sets of factors: (i) attitudes or preferences, (ii) norms and (iii) constraints and opportunities. These three sets of factors correspond with the main sets of influences on individual behaviours that are identified by many theoretical orientations within the social sciences (Elster 1989; Featherman et al. 1984). As such, they sensitise the users of the TPB to the fact that fertility intentions and behaviour are influenced by a complex mix of attitudes ("How do I feel about parenthood?"), norms ("How do relevant others feel about me being a parent?") and constraints ("What factors facilitate and hinder my becoming a parent?") Second, the distinction between perceived behavioural control and actual behavioural control that is made in the TPB is important because it reminds researchers that constraints and opportunities operate in two different ways. One the one hand, individuals may be aware of the constraints and opportunities facing them and adapt their behaviour accordingly. On the other hand, constraints and opportunities may partially operate 'behind the backs' of individuals, constraining their behaviour without them being aware, or with individuals only finding out about the constraints once they try to realise their intentions. Third, the TPB sensitises users to think about the mechanisms linking so-called "background factors" and fertility. Why does an educational gradient in rates of first childbearing exist in many countries (Kravdal and Rindfuss 2008)? The TPB points out that what differentiates lower and higher educated could be differences in attitudes, differences in norms and differences in opportunities and constraints - or any combination of these three mechanisms.

If the TPB is more useful as a heuristic framework for understanding fertility than as a theory, the next question is whether it has the proper level of abstraction as a framework. MandB feel that it is not abstract enough and suggest it is too 
parsimonious. At first glance, this seems a rather ironic position, as the TPB is usually criticised as being too complex rather than too parsimonious, for instance by McGuire (1986, p.111), who states "One wonders if so onerous a procedure is ever used except perhaps by a peculiarly deliberative person in an unusually important yet leisurely choice situation" (McGuire 1986, p.111). If one reflects upon the differences between the TPB and the Theory of Conjunctural Action (TCA) that MandB (Johnson-Hanks et al. 2011) advocate, it is clear that the latter theory is way more abstract than the TPB. In my view, this is a disadvantage rather than an advantage, as the 'gap' between the theoretical framework and empirical research inspired by it is much smaller for the TPB than for the TCA. I would expect the TCA to suffer from the same weakness as other grand theoretical designs - e.g. Giddens's structuration theory $(1979,1992)$ - in that they offer very interesting abstract insights about part of social reality, but that it is extremely hard to translate these insights into empirical research.

\section{The notion of 'intention'}

A second criticism of the TPB made by MandB is that the TPB focuses on intentional processes only, and that this is unfortunate given that fertility often is the outcome of non-intentional processes. I tend to agree with MandB that fertility can be the outcome of non-intentional processes. At the same time, I feel that the focus on intentions in the TPB is much less detrimental to our understanding of fertility behaviour than MandB suggest. First, it is only natural that models of human behaviour start from the assumption of human agency (Hitlin and Elder 2007). At the same time, such models should not take human agency for granted. Therefore, the TPB allows to test to what extent intentions influence behaviour. Although earlier research has shown that intentions do not fully explain subsequent behaviours, intentions are usually found to be the strongest predictors of these behaviours. Second, if an intention-behaviour discrepancy is observed, this asks for an explanation, and as such it acts as a starting point for searching for alternative explanations (Philipov 2009). These alternative explanations could refer to changing opportunities - "actual behavioural control" in the TPB - or to unintentional processes. Third, too much emphasis might be put on the role of intentions in the TPB. Demographers are really interested in fertility behaviour rather than in fertility intentions and they often use intentions as a proxy for behaviour if they only have access to cross-sectional data. I would argue that the TPB still is a very useful heuristic framework even when intentions are disregarded. The model would still sensitise the user to the fact that actual behaviour is influenced by attitudes, norms, perceived and actual behavioural control (Billari and Liefbroer 2007; Liefbroer 2005).

\section{The alleged static nature of the TPB}

MandB suggest that the TPB is static, as it cannot accommodate changing intentions over the life course. According to MandB, the TPB is also unable to 
explain changes in beliefs and attitudes over the life course. I clearly disagree with this assessment. The TPB is perfectly suited to incorporate change. In fact, it can easily be combined with a life-course perspective on fertility decisionmaking. A first way in which the TPB is dynamic is by incorporating feedback mechanisms. In their 1975 book in which Fishbein and Ajzen introduced their theory of reasoned action, they already included feedback arrows from behaviour back to attitudes and norms (Fishbein and Ajzen 1975, Figure 1.2 on p.16). These arrows suggest that people will re-evaluate their attitudes and norms based on their actual fertility experiences. A second way in which the TPB is dynamic is by its insistence on the fact that background characteristics influence attitudes, norms and perceptions of control. If these background characteristics change across the life course, this will lead to changes in norms, attitudes and control perceptions in their wake, with potential revisions in intentions and behaviour as an ultimate consequence. Thus, there is nothing inherently static in the TPB. Rather, examining change in attitudes, norms and intentions over time is one of the most interesting opportunities that the TPB offers. For instance, using multiple waves of the Generations and Gender Survey (Vikat et al. 2007) does not only allow for the study of the extent to which intentions are realised, but also allows for the examination of whether the attitudes, norms and perceived constraints on childbearing have changed. If so, one could analyse whether this is related to the changing life course position of individuals or whether more generic societal changes are at play.

\section{Macro-micro influences}

The final issue that MandB raise is that the TPB cannot incorporate the influence of social contexts on fertility behaviour. Again, I disagree. In fact, social contexts can influence the elements of the TPB in myriad ways (see Klobas 2010). The social context feeds into the attitudes and norms that people have. This can be viewed as a the outcome of a continuous process of socialisation that starts during childhood, but is not restricted to the early phases of life. Rather, people will reassess norms, attitudes and perceived behavioural control during later phases of the life course as well, provided that significant changes in the social context occur. For instance, consider the consequences of a change in the economic climate in a society. One way in which such a change could influence the decision-making process is by changing individuals' attitudes, because the consequences of having a child for their spending power or their job security would be assessed more negatively. It could also lead to a decrease in individuals' sense of behavioural control, as the preconditions needed to engage in family formation become less secure. Norms could also be influenced as individuals may pay more attention to the normative considerations of relevant members of their networks. Additionally, such changes in the economic climate could lead to a weakening of the intention-behaviour relationship, as a worsening economic climate increases the chances of union dissolution (Fischer and Liefbroer 2006) 
and thus of a change in the actual behavioural control over fertility. The same kind of reasoning could be applied in case of other major societal changes, such as a shift in child care arrangements within society. As this example makes clear, societal contexts operate in two analytically distinct ways. First, changing contexts may change the attitudes, norms and perceptions of behavioural control. Even with the strength of the links between these elements and intentions and behaviour remaining constant, this could lead to changes in intentions and behaviour. Second, changing contexts may influence the weight attached to different elements in the model. For instance, if formal child care arrangements improve, the reliance of individuals on informal care may decrease, leading to a decrease in the weight attached to norms in constructing intentions and behaviour. As these examples show, the TPB allows societal change to influence fertility decision-making in multiple ways. Thus, rather than hampering our understanding of the ways in which contexts influence fertility, it stimulates thinking about the macro-micro relationship.

\section{Conclusion}

Morgan and Bachrach (2011) argue that the Theory of Planned Behaviour has serious defects for acting as a useful theory to explain human fertility. I disagree with their general assessment. The TPB incorporates the main determinants of social behaviour-preferences, norms and constraints-and stimulates thinking about their interrelationship. The TPB is dynamic and allows for creative thinking about links between the societal and individual level. Demographers should be aware, however, about the different ways in which the TPB can be used. First, it can be used as a theory that one wants to test. Although absolutely legitimate, I feel that testing the TPB as such is not a very useful activity for demographers-although it might be for psychologists! It is not particularly interesting to find that attitudes, norms and control perceptions matter for fertility intentions and behaviour. What is interesting to demographers, though, is getting answers to questions like (a) what considerations about the consequences of having a child matter, (b) whether parents or peers are more influential in fertility decision-making, and (c) what do people perceive to be the most important societal constraints on childbearing? The TPB cannot provide answers to these questions, as the selection of relevant beliefs, norms and perceived constraints has to be guided by substantive theory and reasoning. However, the TPB as a heuristic framework is perfectly suited to illuminate the linkages between all those types of questions, to raise awareness about the different types of building blocks to be included in any explanation and to offer useful suggestions for translating these ideas into feasible survey instruments. As such, it can be an invaluable tool in increasing our understanding of human fertility decision-making. 


\section{References}

Ajzen, I. 1985. From intentions to actions: a theory of planned behavior. In Action control: from cognition to behaviour, ed. J. Kuhl and J. Beckmann, 11-39. Berlin: Springer.

Billari, F.C., and A.C. Liefbroer 2007. Should I stay or should I go? The impact of age norms on leaving home. Demography 44: 181-198.

De Bruijn, B.J. 1999. Foundations of demographic theory. Choice, process, context. Amsterdam: Thela Thesis.

De Jong-Gierveld, J. and A.C. Liefbroer 1988. Transitions in young-adult life: a choicemodel approach. In European contributions to youth research, ed. J.L. Hazekamp, W. Meeus and Y. te Poel, 161-174. Amsterdam: Free University Press.

Dommermuth, L., J. Klobas and T. Lappegard 2011. Now or later? The theory of planned behavior and timing of fertility intentions. Advances in Life Course Research 16: 42-53.

Elster, J. 1989. The cement of society: a study of social order. New York/Cambridge: Cambridge University Press.

Featherman, D.L., D.P. Hogan and A.B. Sorensen 1984. Entry into adulthood: profiles of young men in the 1950s. In Life-span development and behavior, ed. P.B. Baltes and O.G. Brim Jr., 6: 159-202. Orlando: Academic Press.

Fishbein, M. and I. Ajzen 1975. Belief, attitude, intention and behavior: an introduction to theory and research. Reading, MA: Addison-Wesley.

Fishbein, M. and I. Azjen 2010. Predicting and changing behavior. New York: Taylor and Francis.

Fischer, T., and A.C. Liefbroer 2006. For richer, for poorer: the impact of macroeconomic conditions on union dissolution rates in the Netherlands 1972-1996. European Sociological Review 22: 519-532.

Giddens, A. 1979. Central problems in social theory. Action, structure and contradiction in social analysis. London: MacMillan.

Giddens, A. 1992. The transformation of intimacy. Sexuality, love and eroticism in modern societies. Cambridge: Polity Press.

Hitlin, S. and G.H. Elder 2007. Time, self and the curiously abstract concept of agency. Sociological Theory 25: 170-191.

Johnson-Hanks, J., C. Bachrach, S.P. Morgan and H.P. Kohler 2011. Understanding family change and variation: structure, conjuncture, and action. New York: Springer.

Klobas, J. 2010. Social psychological influences on fertility intentions: a study of eight countries in different social, economic and policy contexts. Milano: Dondena Centre, Bocconi University (REPRO Deliverable 3.18).

Kravdal, O. and R.R. Rindfuss 2008. Changing relationships between education and fertility: a study of women and men born 1940 to 1964. American Sociological Review 73: 854-873.

Liefbroer, A.C. 2005. The impact of perceived costs and rewards of childbearing on entry into parenthood: evidence from a panel study. European Journal of Population 21: 367-391.

Liefbroer, A.C., L. Gerritsen and J. de Jong Gierveld 1994. The influence of intentions and life course factors on union formation behavior of young adults. Journal of Marriage and the Family 56: 193-203. 
Liefbroer, A.C. and J. de Jong Gierveld 1993. The impact of rational considerations and perceived opinions on young adults' union formation intentions. Journal of Family Issues 14: 213-235.

McGuire, W.J. 1986. The vicissitudes of attitudes and similar representational constructs in twentieth century psychology. European Journal of Social Psychology 16: 89-130.

Merton, R.K. 1968. Social theory and social structure. 1968 enlarged edition. New York: The Free Press.

Morgan, S.P. and C.A. Bachrach 2011. Is the Theory of Planned Behaviour an appropriate model for human fertility? Vienna Yearbook of Population Research Vol 9:11-18.

Philipov, D. 2009. Fertility intentions and outcomes: the role of policies to close the gap. European Journal of Population 25: 355-361.

Stinchcombe, A.L. 1968. Constructing social theories. New York: Harcourt, Brace and World.

Swanborn, P.G. 1990. The changing concept of theory. In Operationalization and research strategy, ed. J.J. Hox and J. de Jong-Gierveld, 17-32. Amsterdam: Swets and Zeitlinger.

Vikat, A., Z. Spéder, G. Beets, F.C. Billari, C. Bühler, A. Désesquelles, T. Fokkema, J.M. Hoem, A. MacDonald, G. Neyer, A. Pailhé, A. Pinnelli and A. Solaz 2007.

Generations and gender survey (GGS): towards a better understanding of relationships and processes in the life course. Demographic Research 17: 389-440. 